\title{
LOVE NOTES FROM THE SHIFTLESS
}

As the universe travels outward so could a brick, inert in the sunlight passed through a window to a rubble-littered floor,

explode; and the abandoned house for which it served as heart, assume the centrifugal shape and spin of a pinwheel, but a pinwheel we couldn't recognize in its enormity, the space between one pinwheel-unit and the next continually increasing as the house's hundred bolts shot

through the air; and we could live, make love, and spend our waning days unknowing we twined limbs in the interval between two unseen quantums

of a pinwheel-pattern expanding with ferocity through the cosmos; and the whole phenomenon, like any home-made bomb, innocently touched

off by a heat no greater than this my erection in this your acceptance of it. And so there seems to be rationale for lolling, to do nothing

but siphon the vapor condensing above a love-stained mattress-or, say, the meat deliquescing inside a peachfrom somewhere out of you, into you, through you: as if, or maybe really, re-establishing osmotic balance in some neighborhood ecology. And on this block love works 
this way, the deep kind, no

fireworks; but the passive opening

onto luminescence, lax to take

and give light, charged

not like a battery

-like a hole drilled

long ago in a board

nailed, longer ago,

to a roseate eastern exposure. 